\title{
Gene expression profiling of high altitude polycythemia in Han Chinese migrating to the Qinghai-Tibetan plateau
}

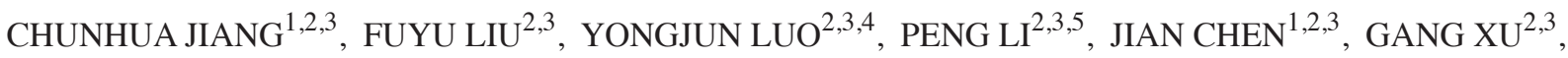 \\ YUJIE WANG ${ }^{1,2,3}$, XIAOXU LI ${ }^{2,3}$, JIAN HUANG ${ }^{1,2,3}$ and YUQI GAO ${ }^{1,2,3}$ \\ ${ }^{1}$ Department of Pathophysiology and High Altitude Physiology, College of High Altitude Military Medicine, \\ Third Military Medical University; ${ }^{2}$ Key Laboratory of High Altitude Medicine, Ministry of Education; \\ ${ }^{3}$ Key Laboratory of High Altitude Medicine, PLA; ${ }^{4}$ Department of High Altitude Disease, College of High Altitude \\ Military Medicine, Third Military Medical University; ${ }^{5}$ Department of High Altitude Military Hygiene, \\ College of High Altitude Military Medicine, Third Military Medical University, Chongqing 400038, P.R. China
}

Received June 24, 2011; Accepted September 26, 2011

\section{DOI: $10.3892 / \mathrm{mmr} .2011 .632$}

\begin{abstract}
Chronic mountain sickness (CMS) is a condition in which the hematocrit is increased above the normal level in residents at high altitude. High altitude polycythemia (HAPC) is the most characteristic sign of CMS. However, the pathogenesis of HAPC is poorly understood. The present study aimed to investigate the gene expression profile of HAPC in Han Chinese migrating to the Qinghai-Tibetan Plateau and to identify the pathogenetic mechanisms. A total of 9 differentially expressed genes were identified in HAPC patients using microarrays: 5 were up-regulated and 4 were down-regulated. Functional analysis of the array data revealed that cell division cycle 42 (CDC42) and the human immune response may be key features underlying the mechanism and development of HAPC.
\end{abstract}

\section{Introduction}

Immigration from the plain to the plateau results in a compensatory increase in the number of red blood cells (RBC), which facilitates acclimatization to hypobaric hypoxia (1-4).

Correspondence to: Dr Y. Gao, College of High Altitude Military Medicine, Third Military Medical University, No. 30 Gao Tan Yan Zheng Street, Sha Ping Ba, Chongqing 400038, P.R. China

E-mail: gaoy66@yahoo.com

Abbreviations: HAPC, high altitude polycythemia; CMS, chronic mountain sickness; HIF-1, hypoxia inducible factor 1; EPO, erythropoietin; HSC, hematopoietic stem cell; BFU-E, erythroid blast-forming unit; CFU-E, erythroid colony-forming unit; CDC42, cell division cycle 42; RBC, red blood cell; CYP1B1, cytochrome P450, family 1, subfamily B, polypeptide 1; ERAP2, endoplasmic reticulum aminopeptidase 2; CLC, Charcot-Leyden crystal protein; JNK, c-Jun-NH2-terminal kinases; ROS, reactive oxygen species; ECM, extracellular matrix

Key words: altitude, hypoxia, polycythemia, chronic mountain sickness, gene expression profiling, microarray
Increasing the number of RBCs enables the lungs to obtain more atmospheric oxygen (3). The increased number of RBCs stabilizes at a certain level during long term-exposure to high altitudes in the majority of individuals; however, in others the number of RBCs continues to increase, causing serious clinical symptoms and signs, known as high altitude polycythemia (HAPC).

International diagnostic guidelines for HAPC were adopted by the 6th International Conference on High Altitude Medicine in 2004 (5). HAPC is characterized by excessive erythrocytosis (females, $\mathrm{Hb} \geq 19 \mathrm{~g} / \mathrm{dl}$; males, $\mathrm{Hb} \geq 21 \mathrm{~g} / \mathrm{dl}$ ) and occurs in natives or long-term residents above 2,500 m (5). Excessive erythrocytosis can increase blood viscosity, reduce blood flow velocity and aggravate hypoxemia (4). On the plateau $(3,000-4,700 \mathrm{~m})$, the incidence of HAPC is $2.43-37.5 \%$ and increases with elevation (6). Furthermore, the incidence of HAPC is significantly higher in migrants to a plateau than in the native population. The incidence of HAPC in males is also markedly higher than in females and is associated with work intensity (6-10).

High altitude hypobaric hypoxia is the primary cause of HAPC, but the pathogenesis is unknown. Upon exposure to high altitude, hypoxia inducible factor 1 (HIF-1) increases erythropoietin (EPO) mRNA levels by binding the EPO promoter, resulting in increased EPO secretion (11). Erythroid progenitor cells are the main targets of EPO and are very sensitive to this molecule (12). An in vitro study showed that erythroid progenitor cells from HAPC patients were more sensitive to EPO than those from healthy migrants (13). However, our previous investigation showed that the increase in RBCs did not always correlate with serum EPO levels (14). Under conditions of hypobaric hypoxia, the number of RBCs can increase at the same time as serum EPO levels are decreasing (14). Therefore, we speculated that the EPO-EPOR system may be associated with erythroid progenitor cell proliferation and differentiation soon after exposure to a plateau. Subsequently, other factors may also be involved in the regulation of erythropoiesis in the bone marrow, and multiple factors working together contribute to excessive RBC proliferation during long term-exposure to high altitudes. Therefore, we 
Table I. Living habits and clinical data for subjects whose RNA was used for microarray analysis.

\begin{tabular}{lccccccc}
\hline Cases & $\begin{array}{c}\text { Age } \\
\text { (years) }\end{array}$ & $\begin{array}{c}\text { Birthplace } \\
\text { (province) }\end{array}$ & Occupation & $\begin{array}{c}\text { Time on plateau } \\
\text { (months) }\end{array}$ & $\begin{array}{c}\text { Qinghai } \\
\text { CMS scores }\end{array}$ & $\begin{array}{c}\text { Oxygen } \\
\text { saturation (\%) }\end{array}$ & $\begin{array}{c}\text { Hemoglobin } \\
(\mathrm{g} / \mathrm{dl})\end{array}$ \\
\hline HAPC1 & 22 & Hubei & Cook & 24 & 6 & 92 & 22.5 \\
Control1 & 29 & Hubei & Cook & 24 & 4 & 92 & 18.8 \\
HAPC2 & 25 & Sichuan & Operator & 30 & 8 & 86 & 21.7 \\
Control2 & 31 & Sichuan & Operator & 30 & 5 & 92 & 18.9 \\
HAPC3 & 24 & Jilin & Operator & 12 & 9 & 90 & 22.0 \\
Control3 & 20 & Jilin & Operator & 12 & 5 & 89 & 18.6 \\
HAPC4 & 23 & Gansu & Maintenance worker & 8 & 11 & 86 & 23.9 \\
Control4 & 19 & Gansu & Maintenance worker & 8 & 0 & 90 & 18.1 \\
HAPC5 & 27 & Shanxi & Cook & 12 & 6 & 84 & 21.8 \\
Control5 & 32 & Shanxi & Cook & 12 & 5 & 92 & 18.7 \\
\hline
\end{tabular}

compared the global gene expression profiles of leukocytes from HAPC patients with those from matched controls to identify disease-specific molecular signatures and candidate molecules involved in the pathophysiology of HAPC.

\section{Materials and methods}

Ethical approval. The investigation followed the principles outlined in the Declaration of Helsinki for the use of human blood and was approved by the Ethics Committee of the Third Military Medical University. Informed consent was obtained from all subjects. Each subject was assigned a unique patient number, which was used thereafter for the protection of privacy.

Subjects. Subjects were divided into two groups: 5 male Han Chinese patients with HAPC (diagnosed according to the International Consensus Statement on HAPC) and 5 matched controls. The subjects were migrants to the TuoTuo River area (Qinghai-Tibetan Plateau, 4,550 m) (5). Living habits and clinical data were collected and deposited into a database (Table I). Each of the 5 HAPC patients was matched to a control according to gender, nationality, birthplace, length of time on the plateau, height of location and work intensity. Anti-coagulated peripheral blood samples were obtained from subjects at 4,550 m. The hemoglobin concentration was measured three times using the $\mathrm{HiCN}$ method and a spectrophotometer (Ehaihuicheng Inc., Shanghai, China). After centrifuging at 1,000 rpm for 10 minutes, the leukocytes were collected and mixed with three volumes of RNA-preservation fluid (Bioteke Inc, Beijing, China) and stored in liquid nitrogen ready for RNA extraction. The gene expression profiles of the RNAs were then analyzed using a Human Genome U133 Plus 2.0 Array (Affymetrix, Santa Clara, CA, USA). Peripheral blood and plasma samples were obtained from a second batch of subjects (13 HAPC patients and 13 matched controls) from the $\mathrm{NaQu}$ area (Qinghai-Tibetan Plateau, 4,610 m). Peripheral blood samples were treated as described above and the gene expression data were confirmed using qRT-PCR.
RNA extraction. RNA extraction and microarray analysis for the first-batch subjects were performed as previously described (15). Total RNA was extracted using the Trizol reagent (Invitrogen, Shanghai, China) and purified using the RNeasy MinElute Cleanup Kit (Qiagen, Beijing, China) according to the manufacturer's instructions. Total RNA from the second batch of subjects was extracted using the TRIpure LS Reagent (BioTeke, Beijing, China) for qRT-PCR. Only RNA with a $28 \mathrm{~S} / 18 \mathrm{~S}$ ribosomal RNA ratio between 1.0 and 1.5 was used in the microarray assay and qRT-PCR experiments.

Microarray analysis. As previously described (15), an aliquot $(2 \mu \mathrm{g})$ of total leukocyte RNA was used to synthesize double-stranded cDNA, which was subsequently transcribed into biotin-tagged cRNA using the MessageAmp aRNA Amplification Kit (Ambion, TX, USA). The cRNA was then fragmented to produce strands of 35-200 bases in length according to the Affymetrix protocol. The fragmented cRNA was then hybridized to the Human Genome U133 Plus 2.0 Array. Microarray hybridization was performed at $45^{\circ} \mathrm{C}$ for 16 hours in an Affymetrix GeneChip Hybridization Oven. The arrays were then washed and stained with streptavidin-phycoerythrin in an Affymetrix Fluidics Station 450 and scanned with an Affymetrix GeneChip Scanner 3000 to analyze the hybridization data. The scanned images were assessed by visual inspection and then analyzed with Affymetrix GeneChip Operating Software (version 1.4). dChip software was used in a global scaling procedure to normalize the different arrays. A two-class unpaired method from the Significance Analysis of Microarrays software (SAM version 3.02, Stanford University) was used to compare differentially expressed genes in the HAPC and control groups.

$q R T-P C R$. qRT-PCR was performed on three genes differentially expressed in the microarray and two c-Jun-NH2-terminal kinases (JNK). The latter (not included in the microarray) may be involved in apoptosis of hemopoietic stem cells (HSCs). Total RNA extracted from the second batch of peripheral blood samples was used to confirm the microarray data by $\mathrm{qRT}-\mathrm{PCR}$. After priming with random primers at $65^{\circ} \mathrm{C}$ 
Table II. Primer sequences and annealing temperatures used for qRT-PCR.

Gene Sequence (5'-3')
Annealing temperature Amplicon size

$\left({ }^{\circ} \mathrm{C}\right)$

(bp)

Major histocompatibility complex, class II, DQ $\beta$ 1(HLA-DQB1)

Farnesyltransferase, CAAX box, $\beta$ (FNTB)

Cell division cycle 42 (CDC42)

$\begin{array}{lll}\text { F } & \text { GCCCTCAACCACCACAACCT } & 6 \\ \text { R } & \text { GGAGTCATTTCCAGCATCACCAG } & \\ \text { F } & \text { AAGAGGCCTTCGACAACTGA } & \\ \text { R } & \text { ACTATCTGGGGGATGGGTTC } & \\ \text { F } & \text { ACGACCGCTGAGTTATCCAC } & \\ \text { R } & \text { CCCAACAAGCAAGAAAGGAG } & \\ \text { F } & \text { TAGGCTCAGGAGCTCAAGGA } & 60 \\ \text { R } & \text { TGAAATGGTCGGCTTAGCTT } & \\ \text { F } & \text { AGGCGAGGGATCTGAAACTT } & \\ \text { R } & \text { AATTGGTTTCAGCTGCTGGT } & \\ \text { F } & \text { GACTTAGTTGCGTTACACCCTTTCT } & 6 \\ \text { R } & \text { GCTGTCACCTTCACCGTTCC }\end{array}$

64 173

60

60

60

91

60

150

62

$\beta$-actin

R GCTGTCACCTTCACCGTTCC for 5 min followed by a 1-min incubation on ice, cDNA was synthesized from $500 \mathrm{ng}$ total RNA using M-MLV reverse transcriptase (ReverTra Ace, Toyobo, Japan), RNase inhibitors and a cocktail of dNTPs in a $20 \mu \mathrm{l}$ reaction volume at $30^{\circ} \mathrm{C}$ for $10 \mathrm{~min}$, followed by incubation at $42^{\circ} \mathrm{C}$ for $20 \mathrm{~min}$ and $99^{\circ} \mathrm{C}$ for $5 \mathrm{~min}$. The resulting cDNA was amplified by qRT-PCR using the Opticon Monitor 3 system according to the manufacturer's instructions (MJ Research, USA). Reactions were performed in a $25-\mu \mathrm{l}$ volume with $1 \mu \mathrm{l}$ of primers and $12.5 \mu \mathrm{l}$ hot start reaction mix SYBR Green (Takara, Dalin, China). The reactions were repeated three times. The PCR conditions were: $2 \mathrm{~min}$ at $95^{\circ} \mathrm{C}$ followed by 40 cycles of $15 \mathrm{sec}$ at $95^{\circ} \mathrm{C}, 15 \mathrm{sec}$ at the annealing temperature and $15 \mathrm{sec}$ at $72^{\circ} \mathrm{C}$. The PCR primer sequences and the annealing temperatures are listed in Table II. Amplification specificity was checked using melting curve analysis. Gene expression was normalized against that of $\beta$-actin.

Detection of $\mathrm{Hb}, \mathrm{ROS}, \mathrm{CLC}$ and EPO. The hemoglobin concentration in the blood from the second-batch subjects was assessed as described above. The levels of plasma Charcot-Leyden crystal protein (CLC), reactive oxygen species (ROS) and EPO in the blood of the second batch subjects were measured twice using an ELISA (Uscn Life Science Inc., Wuhan, China), fluorescence labeling (GenMed Scientifics Inc., Shanghai, China) and a radioimmunoassay kit (PuerWeiye Inc., Beijing, China), respectively, according to the manufacturer's instructions.

Statistical analysis. Data were expressed as the mean \pm SD. Student's t-test was used to calculate the statistical significance of unpaired data where appropriate. Statistical significance was defined as $\mathrm{p}<0.05$.

\section{Results}

Microarray data. After SAM analysis of the microarray data obtained from the 5 HAPC patients and 5 matched controls, 9 differentially expressed genes were identified with a thresholdfold change $>2.0$. These genes were used for unsupervised hierarchical clustering and the results were analyzed and visualized using the TreeView program (Fig. 1). The functions of the differentially expressed genes were analyzed using a Web-based program, Molecular Annotation System 3.0 (www. capitalbio.com) and three separate open source pathway resources: KEGG, BioCarta and GenMAPP. Table III lists the significant pathways associated with hematopoiesis.

Verification of differential expression by $q R T-P C R$. The mRNA expression levels of 3/9 differentially expressed genes were assayed. The expression levels of the genes (as detected by real-time reverse transcriptase PCR) were consistent with the results obtained from the microarrays, although there were minor discrepancies (Table IV). Moreover, the expression level of JNK1 and JNK2 mRNA in HAPC patients was significantly lower than that in the controls.

$H b, R O S, C L C$ and EPO concentrations. As shown in Fig. 2, the concentration of hemoglobin in HAPC patients was significantly higher than that in the matched controls; however, the concentration of CLC was markedly lower than that in the controls. There was no significant difference in plasma ROS and EPO levels between the two groups (Fig. 2).

\section{Discussion}

The Affymetrix Human Genome U133 Plus 2.0 microarray contains 47,000 transcripts and covers the majority of known human genes. In this study, we used whole genome microarray analysis to gain a comprehensive understanding of the pathogenesis of HAPC. This is the first report analyzing global gene expression in HAPC patients; 9 differentially expressed genes were identified.

CDC42, a Rho GTPase, is associated with HSC morphology, adhesion, migration, mobilization and erythropoiesis in the bone marrow (16-20). Yang et al observed that 


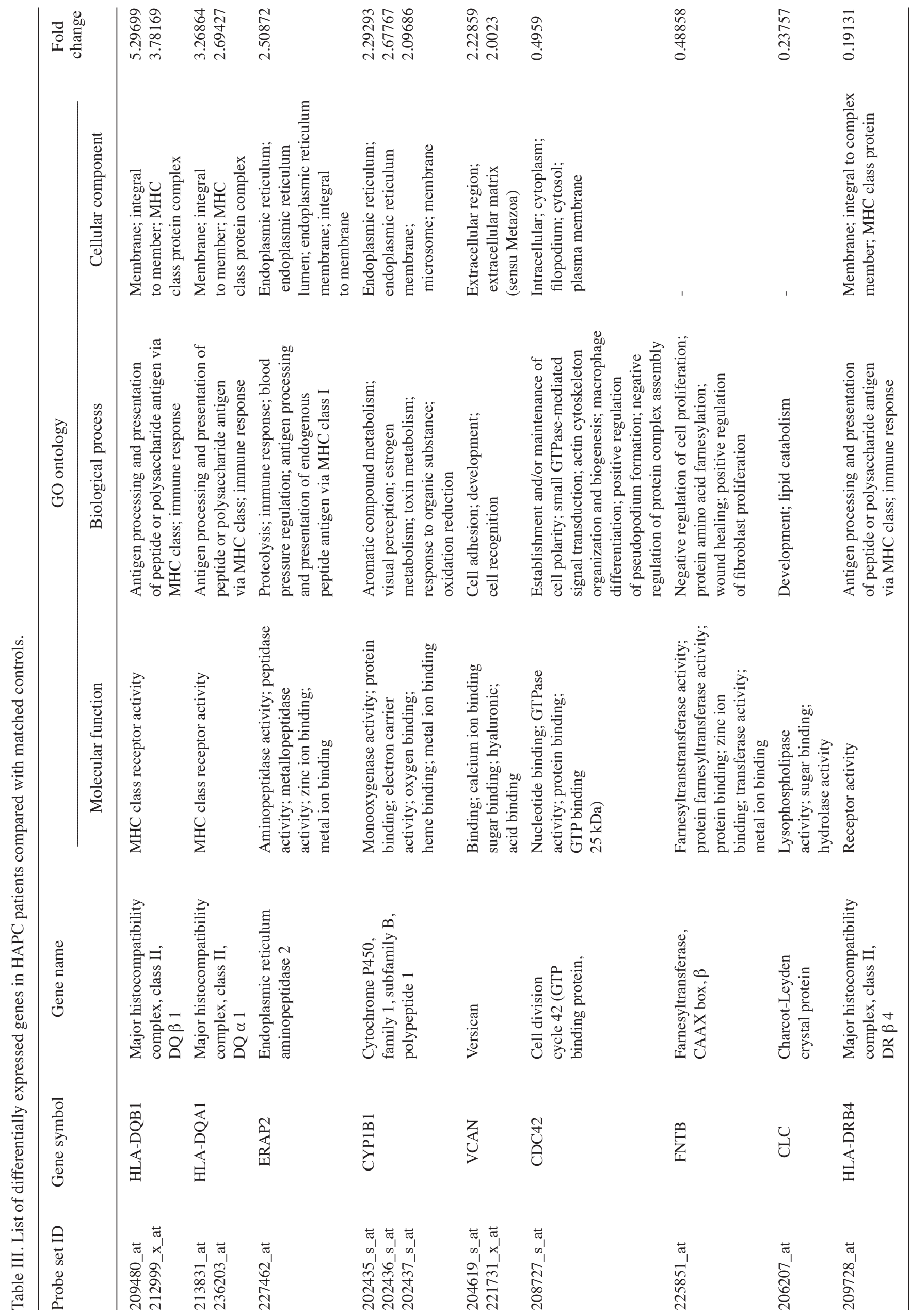


Table IV. mRNA expression in HAPC patients compared with that in controls as assessed by microarray analysis and qRT-PCR .

\begin{tabular}{llcc}
\hline Gene & \multirow{2}{*}{ Probe set ID } & \multicolumn{2}{c}{ Fold change } \\
\cline { 3 - 4 } & & Microarray & qRT-PCR \\
\hline HLA-DQB1 & 209480_at & 5.30 & 4.50 \\
FNTB & 225851_at & 0.49 & 0.56 \\
CDC42 & 208727_s_at & 0.50 & 0.70 \\
JNK1 & - & - & 0.58 \\
JNK2 & - & - & 0.67 \\
\hline
\end{tabular}

$\mathrm{CDC} 42^{-/} \mathrm{HSCs}$ enter the active cell cycle, resulting in significantly increased numbers of stem/progenitor cells in the bone marrow (16). They also found that increased CDC42 activity caused a significant reduction in the number of HSCs and reduced erythroid blast-forming unit (BFU-E) and erythroid colony-forming unit (CFU-E) activity, which are mediated by the JNK pathway and induce apoptosis of HSCs (16). They therefore hypothesized that CDC42 activity is crucial for erythropoiesis and numerous HSC functions. In the present study, CDC42, JNK1 and JNK2 mRNA expression was significantly lower in HAPC patients than in controls. It is therefore possible that a reduction in $\mathrm{CDC} 42$ activity in HAPC patients may result in an increase in the number of BFU-E/CFU-E and reduced apoptosis of HSCs. The microarray and qRT-PCR data revealed that the expression levels of FNTB mRNA in HAPC patients were significantly lower than those in controls. CDC42 undergoes post-translational modification by FNTB to yield a carboxyl-terminal CAAX (where $\mathrm{C}$ represents cysteine, $\mathrm{A}$ is an aliphatic amino acid and $\mathrm{X}$ is any amino acid) signaling motif, which promotes proper localization to the plasma membrane and is required for biological activity (21). Failure of the CAAX modification renders CDC42 inactive due to mislocalization (22). Reduced FNTB expression in HAPC patients may therefore inactivate CDC42, leading to increased erythropoiesis. This indicates that decreased expression of CDC42 and defects in carboxylterminal CAAX modifications (mediated by down-regulation of FNTB) reduce CDC42 activity, which in turn promotes excess erythropoiesis in the bone marrow by affecting HSC adhesion, migration, mobilization and (possibly) apoptosis mediated by JNK1 and JNK2.

Of the 9 differentially expressed genes identified on the microarray, ERAP2, CLC, HLA-DQB1, HLA-DQA1 and HLA-DRB4 are involved in immune responses. ERAP2 is involved in the formation of HLA class I binding peptides (23-26). Suppression of ERAP2 by siRNA reduces the surface expression of HLA class I molecules and affects $\mathrm{T}$ cell presentation of antigenic epitopes (23). Increased expression of ERAP2 mRNA in HAPC patients may promote the expression of HLA class I molecules, which stimulate $\mathrm{CD} 8^{+} \mathrm{T}$ cells to evoke an immune response. Ackerman et al revealed that CLC protein interacts with eosinophil lysophospholipase and inhibits its lipolytic activity (27). Furthermore, CLC is essential for the functional of $\mathrm{CD} 25^{+}$Treg cells (28). Lower levels of CLC mRNA and protein in HAPC patients indicate an

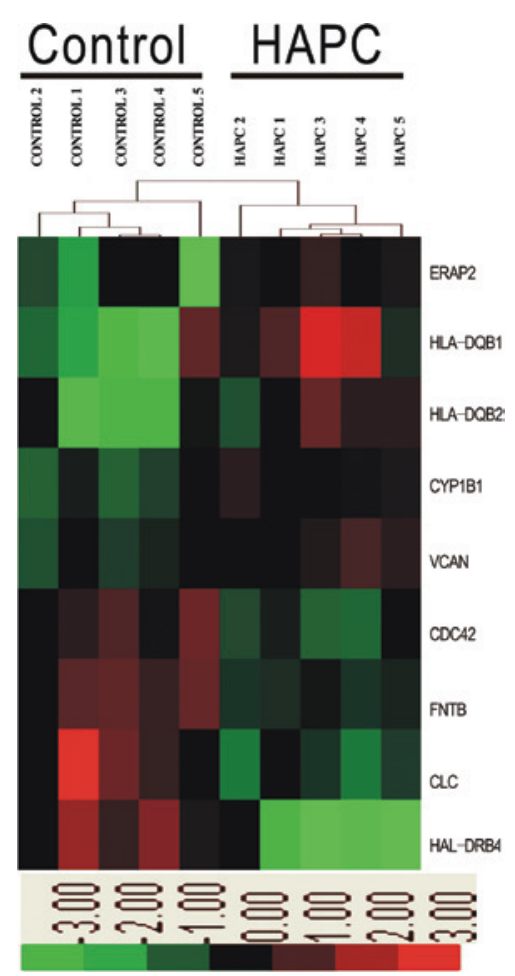

Figure. 1. Clustering display of differentially expressed genes in HAPC patients. Comparison of the nine differentially expressed genes was performed using SAM software and visualized with TreeView following hierarchical clustering. Gene symbols are shown on the right. Expression levels are represented by a color tag, with red representing the highest levels of expression and green the lowest.

altered immune response. Changes in HLA class II molecule (HLA-DQB1, HLA-DQA1 and HLA-DRB4) mRNA expression in HAPC patients indicate that $\mathrm{CD}^{+} \mathrm{T}$ cells are also involved in altered immune responses. However, it is unclear whether these altered immune responses are the cause or the result of HAPC.

Hypoxia is an environmental stressor that affects the autonomic nervous system and endocrine function (29). Several studies have shown that the plasma IL-1, IL-6 and IL-8 levels are elevated under conditions of hypoxia or exposure to high altitudes (30-32), indicating changes in immune function. However, Monterio et al showed that intravenous injection of $\mathrm{CD} 4^{+} \mathrm{T}$ cells increased the number of activated $\mathrm{CD} 4^{+} \mathrm{T}$ cells and their secreted hematopoietic regulatory factors in the bone marrow of athymic nude mice, improving their anemia (33). Alexander et al also showed that $\mathrm{T}$ cell-derived cytokines have marked effects on hematopoiesis (34).

CYP1B1, a member of the cytochrome P450 superfamily, shares activity with monooxygenase, which metabolizes various polycyclic aromatic hydrocarbons, aryl amines and retinoic acid and steroid hormones (35-37). A study of the association between CYP1B1 and peripheral blood lipid levels showed that high density lipoprotein (HDL) levels were significantly lower in patients expressing high levels of CYP1B1 than in those expressing low or medium levels (38). Similarly, high CYP1B1 expression in HAPC patients correlates with low HDL levels. HDL cholesterol levels are a significant factor for determining the lifespan of erythro- 

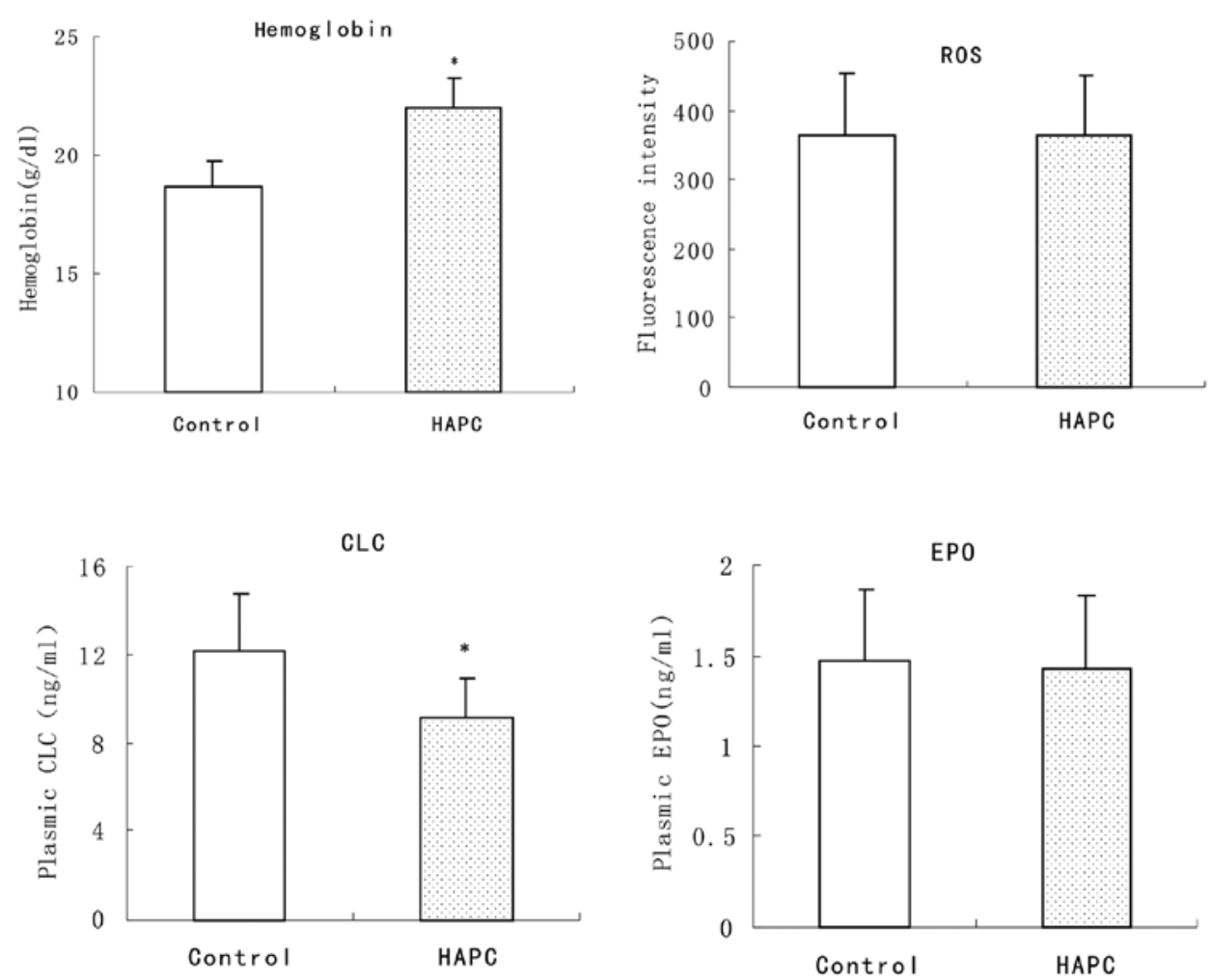

Figure. 2. Concentration of hemoglobin, ROS, CLC and EPO in HAPC patients and controls ( $n=13$ ). (A) The hemoglobin concentration in the HAPC group was higher than that in the controls. (B) There was no difference in the level of plasma ROS between HAPC patients and controls. (C) Plasma CLC level was markedly lower in HAPC patients than in controls. (D) There was no difference in plasma EPO levels between HAPC patients and the controls. "p $<0.05$ compared with the controls.

cytes. High HDL levels cause anemia due to the decreased deformability, increased osmotic fragility and reduced lifespan of erythrocytes (39). Therefore, we propose that decreased CYP1B1 expression in HAPC patients may reduce plasma HDL levels which, in turn, results in increased erythrocyte longevity.

Versican is expressed throughout the body and endows the extracellular matrix (ECM) with hygroscopic properties, creating the loose hydrated matrix necessary to support key events in development and disease (40). Numerous cellular processes including adhesion, proliferation, apoptosis and migration are regulated by versican (41-43). Several functional studies have shown that versican increases cell motility and proliferation (44-46). Up-regulation of versican expression in HAPC patients may increase the pericellular matrix around the cells and expansion of the ECM in the bone marrow, creating a highly malleable extracellular environment that supports HSC proliferation and migration.

The present study found no difference in the plasma levels of ROS and EPO between HAPC patients and controls. This may be due to the small sample size. A larger epidemiologic survey (246 HAPC patients and 716 controls) conducted by our research team showed that plasma ROS and EPO levels were significantly higher in HAPC patients than in controls (data not shown); therefore, we propose that EPO and ROS are involved in the pathogenesis of HAPC.

In summary, nine genes were identified as differentially expressed in HAPC patients, providing clues to the molecular pathogenesis of this condition. Analysis of our array data revealed that CDC42 may play a fundamental role in erythropoiesis in the bone marrow of HAPC patients. However, the exact role of CDC42 in HAPC remains unknown. These data also reveal a complex relationship between HAPC and the immune response, which requires further study.

\section{Acknowledgements}

This work was supported by the 'Eleventh Five-Year' National Technology Support Program of China (no. 2009BAI85B01), the National Science Foundation of China (no. 3097142, no. 81101469) and the National Key Basic Research Program of China (no. 2006CB504101). We thank Professor Li Wang (Institute of Genetics and Developmental Biology, Chinese Academy of Science, Beijing, China) for help with the functional analysis of the differentially expressed genes.

\section{References}

1. Windsor JS and Rodway GW: Heights and haematology: the story of haemoglobin at altitude. Postgrad Med J 83: 148-151, 2007.

2. Ou LC, Salceda S, Schuster SJ, et al: Polycythemic responses to hypoxia: molecular and genetic mechanisms of chronic mountain sickness. J Appl Physiol 84: 1242-1251, 1998.

3. Martin D and Windsor J: From mountain to bedside: understanding the clinical relevance of human acclimatisation to high altitude hypoxia. Postgrad Med J 84: 622-627, 2008.

4. Reeves JT and Leon-Velarde F: Chronic mountain sickness: recent studies of the relationship between hemoglobin concentration and oxygen transport. High Alt Med Biol 5: 147-155, 2004. 
5. Velarde FL, Maggiorini M, Reeves JT, et al: Consensus statement on chronic and subacute high altitude diseases. High Alt Med Biol 6: 147-157, 2005.

6. Beall CM, Brittenham GM, Strohl KP, Blangero J, Williams BS and Goldstein MC: Hemoglobin concentration of high-altitude Tibetans and Bolivian Aymara. Am J Phys Anthropol 106: 385-400, 1998

7. Monge CC, Arrequi A and Leon-Velarde F: Pathophysiology and epidemiology of chronic mountain sickness. Int J Sports Med Suppl 1: s79-s81, 1992.

8. Beall CM, Brittenham GM, Macuaga $F$ and Barragan $M$ Variation in hemoglobin concentration among samples of high altitude natives in the Andes and the Himalayas. Am J Hum Physiol 2: 639-651, 1990

9. Beall CM and Goldstein MC: Hemoglobin concentration of pastoral nomads permanently residing at $4850-5450 \mathrm{~m}$ in Tibet Am J Phys Anthropol 73: 433-438, 1987.

10. Wu TY, Wang XQ, Wei CY, et al: Hemoglobin levels in Qinghai-Tibet: different effects of gender for Tibetans vs. Han. J Appl Physiol 98: 598-604, 2005.

11. Semenza GL, Nejfelt MK, Chi SM and Antonarakis SE: Hypoxia inducible nuclear factors bind to an enhancer element located 3 to the human erythropoietein gene. Proc Natl Acad Sci USA 88 $5680-5684,1991$.

12. Richmond TD, Chohan M and Barber DL: Turning cell red: signal transduction mediated by erythropoietin. Trends Cell Biol 15: 146-155, 2005.

13. Amaru R, Villarroel M, Miguez H, et al: Hematopoietic progenitor cells from patients with chronic mountain sickness lack the JAK(V617F) mutation, show hypersensitivity to erythropoietin and are inhibited by statins. Blood 114: 752, 2009.

14. Li P, Huang J, Tian HJ, Huang QY, Jiang CH and Gao YQ Regulation of bone marrow hematopoietic stem cell is involved in high-altitude erythrocytosis. Exp Hematol 39: 37-46, 2011

15. Zhang Y, Cui Y, Zhou Z, Sha J, Li Y and Liu J: Altered global gene expressions of human placentae subjected to assisted reproductive technology treatments. Placenta 31: 251-258, 2010.

16. Wang L, Yang L, Filippi MD, Williams DA and Zheng Y: Genetic deletion of Cdc42GAP reveals a role of $\mathrm{Cdc} 42$ in erythropoiesis and hematopoietic stem/progenitor cell survival, adhesion, and engraftment. Blood 107: 98-105, 2006.

17. Yang L, Wang L, Geiger H, Cancelas JA, Mo J and Zheng Y: Rho GTPase Cdc42 coordinates hematopoietic stem cell quiescence and niche interaction in the bone marrow. Proc Natl Acad Sci USA 104: 5091-5096, 2007.

18. Ghiaur G, Lee A, Bailey J, Cancelas JA, Zheng Y and Williams DA: Inhibition of RhoA GTPase activity enhances hematopoietic stem and progenitor cell proliferation and engraftment. Blood 108: 2087-2094, 2006.

19. Yang L, Wang L, Kalfa TA, et al: Cdc 42 critically regulates the balance between myelopoiesis and erythropoiesis. Blood 110 3853-3861, 2007

20. Yang FC, Atkinson SJ, Gu Y, et al: Rac and Cdc42 GTPases control hematopoietic stem cell shape, adhesion, migration, and mobilization. Proc Natl Acad Sci USA 98: 5614-5618, 2001

21. Sebti SM and Der CJ: Opinion: Searching for the elusive targets of farnesyltransferase inhibitors. Nat Rev Cancer 3: 945-951, 2003

22. Winter-Vann AM and Casey PJ: Post-prenylation-processing enzymes as new targets in oncogenesis. Nat Rev Cancer 5: 405-412, 2005

23. Saveanu L, Carroll O, Lindo V, et al: Concerted peptide trimming by human ERAP1 and ERAP2 aminopeptidase complexes in the endoplasmic reticulum. Nat Immunol 6: 689-697, 2005.

24. Tanioka T: Human leukocyte-derived arginine aminopeptidase: the third member of the oxytocinase subfamily of aminopeptidases. J Biol Chem 278: 32275-32283, 2003.

25. Haroon $\mathrm{N}$ and Inman RD: Endoplasmic reticulum aminopeptidases: biology and pathogenic potential. Nat Rev Rheumatol 6: $461-467,2010$
26. Jensen PE: Recent advances in antigen processing and presentation. Nat Immunol 8: 1041-1048, 2007.

27. Ackerman SJ, Liu L, Kwatia MA, et al: Charcot-Leyden Crystal Protein(Galectin-10) is not a dual function galectin with lysophospholipase activity but binds a lysophospholipase inhibitor in a novel structural fashion. J Biol Chem 277: 14859-14868, 2002.

28. Jan K, Petra L, Tobias B, Sabine S, Christian B and Eva H: Human $\mathrm{CD} 4{ }^{+} \mathrm{CD} 25^{+}$regulatory $\mathrm{T}$ cells: proteome analysis identifies galectin-10 as a novel marker essential for their anergy and suppressive function. Blood 110: 1550-1558, 2007.

29. Facco M, Zilli C, Siviero M, et al: Modulation of immune response by the acute and chronic exposure to high altitide. Med Sci Sports Exerc 37: 768-774, 2005.

30. Eltzschig HK and Carmeliet P: Hypoxia and inflammation. $\mathrm{N}$ Eng J Med 364: 656-665, 2011

31. Hartmann G, Tschop K, Fischer R, et al: High altitide increases circulating interleukin-6, interleukin-1 receptor antagonist and C-reactive protein. Cytokine 12: 246-252, 2000.

32. Wang JS, Lin HY, Cheng ML and Wong MK: Chronic intermittent hypoxia modulates eosinophil- and neutrophil-platelet aggregation and inflammatory cytokine secrection caused by strenuous exercise in men. J Appl Physiol 103: 305-314, 2007.

33. Monterio JP, Benjamin A, Costa ES, Barcinski MA and Bonomo A: A normal hematopoiesis is maintained by activated bone marrow $\mathrm{CD}^{+} \mathrm{T}$ cell. Blood 105: 1484-1491, 2005

34. Alexander LD and Mark HK: T cell regulation of hematopoiesis. Front Biosci 13: 6229-6236, 2008.

35. Saini S, Hirata H, Majid S and Dahiya R: Functional significance of cytochrome P450 1B1 in endometrial carcinogenesis. Cancer Res 69: 7038-7045, 2009.

36. Murray GI, Taylor MC and Mcfadyen M: Tumor-specific expression of cytochrome P450 CYP1B1. Cancer Res 57: 3026-3031, 1997.

37. Nebert DW, Nelson DR, Coon MJ, et al: The P450 superfamily: update on new sequences, gene mapping, and recommended nomenclature. DNA Cell Biol 10: 1-14, 1991.

38. Hu SW, Lin PP and Chen CC: Association of cytochrome P450 1B1 gene expression in peripheral leukocytes with blood lipid levels in waste incinerator workers. Ann Epidemiol 18: 784-791, 2008

39. Meurs I, Hoekstra M, van Wanrooij EJ, et al: HDL cholesterol levels are an important factor for determining the lifespan of erythrocytes. Exp Hematol 33: 1309-1319, 2005.

40. Theocharis AD, Skandalis SS, Tzanakakis GN and Karamanos NK: Progeoglycans in health and disease: novel roles for proteoglycans in malignancy and their pharmacological targeting. FEBS J 277: 3904-3923, 2010.

41. Wight TN: Versican: a versatile extracellular matrix proteoglycan in cell biology. Curr Opin Cell Biol 14: 617-623, 2002

42. Ricciardelli C, Sakko AJ, Ween MP, Russell DL and Horsfall DJ: The biological role and regulation of versican levels in cancer. Cancer Metastasis Rev 28: 233-234, 2009.

43. Hernandez D, Miquel-Serra L, Docampo MJ, Marco-Ramell A and Bassols A: Role of versican V0/V1 and CD44 in the regulation of human melanoma cell behavior. Int J Mol Med 27: 269-275, 2011.

44. Cattaruzza S, Schiappacassi M, Kimata K, Colombatti A and Perris R: The globular domains of PGM/versican modulate the proliferation-apoptosis equilibrium and invasive capabilities of tumor cells. FASEB J 18: 779-781, 2004.

45. Zheng PS, Wen J, Ang LC, et al: Versican/PG-M G3 domain promotes tumor growth and angiogenesis. FASEB J 18: 754-756, 2004.

46. Lapierre DP, Lee DY, Li SZ, et al: The ability of versican to simultaneously cause apoptotic resistance and sensitivity. Cancer Res 67: 4742-4750, 2007. 